\title{
Effect of surgically facilitated accelerated orthodontics on treatment duration, root resorption and bone density
}

\author{
Faisal Arshad $^{1, *}$, Siddharth Arya $^{2}$, Supreet Thind Kaur ${ }^{3}$, Suma T ${ }^{4}$ \\ ${ }^{1,3}$ Senior Lecturer, ${ }^{2}$ Assistant Professor, ${ }^{4}$ Professor, ${ }^{1,2,4}$ Dept. of Orthodontics, Rajarajeswari Dental College \& Hospital, \\ Bangalore, Karnataka, ${ }^{3}$ Dept. of Periodontics, ${ }^{3} \mathrm{MMU}$ Dental College \& Hospital, Mullana, Punjab, India
}

*Corresponding Author:

Email: faisarshad@gmail.com

\begin{abstract}
Introduction: The use of orthodontic treatment in adult patients for the treatment of malocclusion is becoming more common. But the major disadvantages of conventional orthodontic technique are the time consumed for the treatment (18 - 24 months), root resorption and formation of fenestrations and dehiscence. Periodontally Accelerated Osteogenic Orthodontics (PAOO) is a surgical technique which results in an increase in alveolar bone width, shorter treatment time, increase post-treatment stability, and decrease in the amount of apical root resorption.

Objectives: The objective of the study was to evaluate the effect of Periodontally Accelerated osteogenic Orthodontics (PAOO) with surgical bur and piezicision on: Duration of orthodontic space closure, amount of root resorption, and the bone density.

Materials and Methods: Forty subjects who needed orthodontic treatment were randomly selected and divided into two groups. Group I consists of 20 subjects who were selected for Periodontally Accelerated Osteogenic Orthodontics (PAOO) with surgical bur Group II: consists of 20 subjects who were selected for Periodontally Accelerated Osteogenic Orthodontics (PAOO) with peizocision. Patients were recalled at baseline, 3, 6, 9 and 12 months and were evaluated for amount of retraction, bone density, root resorption and detection of fenestration and dehiscence. Cone Beam Computerised Tomography (CBCT) was used to evaluate the bone density, root resorption and for the detection of fenestration and dehiscence.

Results: In subjects where corticotomy was carried out with surgical bur the treatment time was less as compared to PAOO with peizocision. Group I had a mean retraction of $5.99 \pm 0.5 \mathrm{~mm}$ after 3 months $(\mathrm{p}<0.001)$. Group II had a mean retraction of $7.07 \pm$ $0.35 \mathrm{~mm}(\mathrm{p}<0.001)$ after 3 months. CBCT showed a statistically significant increase in bone density in the both PAOO group with surgical bur and peizocision 12 months after the surgery. Root resorption was negligible in Periodontally Accelerated Osteogenic Orthodontic (PAOO) with surgical bur $(0.34 \mathrm{~mm})$ as compared to PAOO with peizocision $(0.51 \mathrm{~mm})$.

Conclusion: PAOO with surgical bur (Group I) decreases the treatment time as compared to piezocision (Group II). Amount of root resorption in Group I which was around $0.34 \mathrm{~mm}$ and that of Group II was around $0.51 \mathrm{~mm}$ which is very minimal and increase in the bone density was seen in the post-operative CBCT.
\end{abstract}

Keywords: PAOO, Wilckodontics, CBCT, Corticotomy.

\section{Introduction}

In the 1990s, Dr Wilcko, using computed tomography, discovered that reduced mineralization of the alveolar bone was the reason behind the rapid tooth movement following corticotomies. Wilcko brothers used their knowledge of corticotomy and their observations of rapid acceleratory phenomenon to develop their patented Periodontally Accelerated Osteogenic Orthodontics (PAOO) technique in 2001. ${ }^{1}$

According to the American Association of Orthodontists, the length of comprehensive orthodontic treatment "can range from one to three years." Studies on treatment time have found durations ranging from 21-27 months for non-extraction treatment and 25-35 months for extraction treatment. ${ }^{2,3}$ Treatment times are influenced by many factors including type of malocclusion, amount of tooth movement required, mechanics utilized, and patient compliance. ${ }^{4-8}$ With prolonged orthodontic treatment time comes increased risk of root resorption. ${ }^{9,10}$ decalcification, ${ }^{11}$ and periodontal problems. ${ }^{12}$

To shorten the time for tooth movement, orthodontists from around the world have increasingly sought ways to boost orthodontics treatment efficiency.
Some of these procedures include use of lasers or electrical stimulation, vibration, corticision, piezocision and osteotomies. ${ }^{13}$

Many surgical procedures have been combined with conventional orthodontics for better treatment of severe dentoalveolar abnormalities. Among these procedures, surgical alveolar corticotomies have been used for years in correction of malocclusions. ${ }^{14}$ Conventional corticotomy approach causing intentional injury to the cortical bone results in a modification of the bone metabolism, leading to a transient state of osteopenia, described as rapid acceleratory phenomenon (RAP). RAP was demonstrated at the alveolar bone level following corticotomy and would be responsible for rapid tooth movement. ${ }^{15}$

An alternative method to conventional treatment is Piezosurgery. Piezoelectric surgery is a minimally invasive technique that lessens the risk of damage to surrounding soft tissues and important structures such as nerves, vessels, and mucosa. It also reduces damage to osteocytes and permits good survival of bony cells during harvesting of bone. It also maintains a bloodfree operating area because of cavitation of the 
irrigation solution, and gives greater visibility particularly in complex anatomical areas. The piezoelectric bony osteotomy cuts the mineralised tissue without damaging the schneiderian membrane.

The aim of the study was to compare the treatment time, root resorption, bone density before and after Periodontally Accelerated Osteogenic Orthodontics treatment with surgical bur and Periodontally Accelerated Osteogenic Orthodontics with Peizocision.

\section{Materials and Methods}

This is a randomized case controlled clinical trial which was performed on 40 subjects. The study was carried out for a period of one year.

The subjects were selected based on the following inclusion and exclusion criteria.

\section{Inclusion Criteria}

1. Age group of 20-40 years.

2. Systemically healthy individuals.

3. Subjects with at least 20 permanent teeth.

4. Subjects with Angle's Class I malocclusions with bi-maxillary protrusion

\section{Exclusion Criteria}

1. Pregnant and lactating women.

2. Subjects with bleeding disorders and any other systemic diseases which will interfere with the treatment outcome.

3. Subjects with Uncontrolled Diabetes Mellitus

4. Subject who are Smokers.

Study Design: Forty subjects who needed orthodontic treatment were randomly selected. The nature of the study, the need for surgery and the outcome of it were explained to the subject following which a verbal and written consent was obtained.

Group 1: consists of 20 subjects who were selected for periodontally accelerated osteogenic orthodontics (paoo) with surgical bur in both maxillae and mandible

Group 2: consists of 20 subjects who were selected for periodontally accelrated orthodontics (paoo) with peizocision in both maxillae and mandible.

Pre-operative and post-operative study models, photographs and radiographs like Ortho Pantamo Graph (OPG) and Radio Visio Graph (RVG) were recorded from the subject in baseline, 3 months, 6 months and 12 months intervals. Digital calliper was used to measure the retraction space at $0,3,6$ months Cone Beam Computerised Tomography (CBCT) was done at baseline and one year after the surgery. Informed consent was obtained from all the subjects participating in the study.

In each study group and control group, bonding of MBT 0.022" slot bracket was done. Nickel titanium wire was used in initial phase of levelling and aligning. PAOO using surgical bur and Peizocision procedure was done before retraction was initiated (Fig. 1). Extraction space was measured with digital calliper before initiating retraction in both groups. The subjects were recalled at interval of two weeks for replacement of active tie backs. Extraction space was measured at every appointment to determine rate of retraction and amount of space closure. En-masse retraction of upper and lower anterior teeth was carried out with force level of 200-250 grams per side. Force level was calibrated using Dontrix gauge.

Group I Patients- PAOO with surgical bur done in upper and lower arch- (representational images showing the lower arch only)

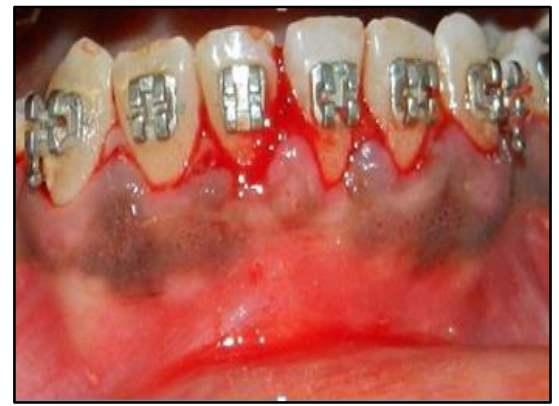

Fig. 1a: PAOO with surgical bur-Incisions given

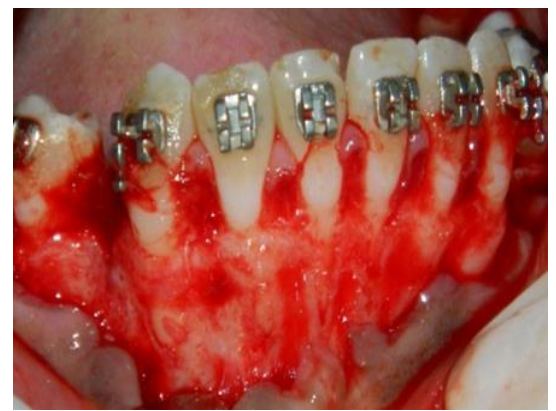

Fig. 1b: Elevation of Full thickness flap

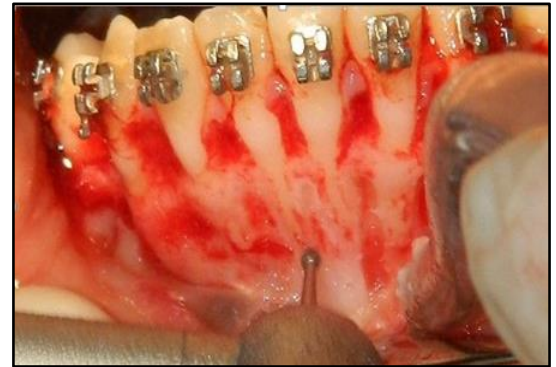

Fig. 1c: Placement of perforations with bur

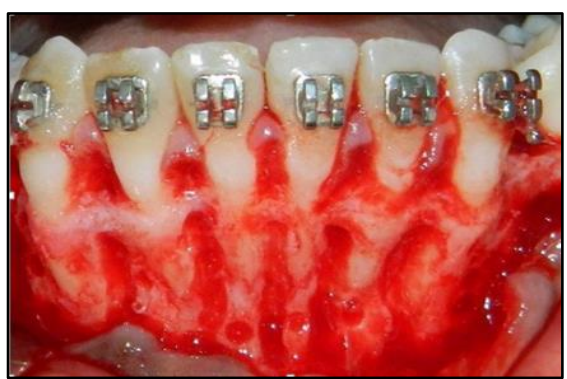

Fig. 1d: Vertical corticotomy and perforations given 


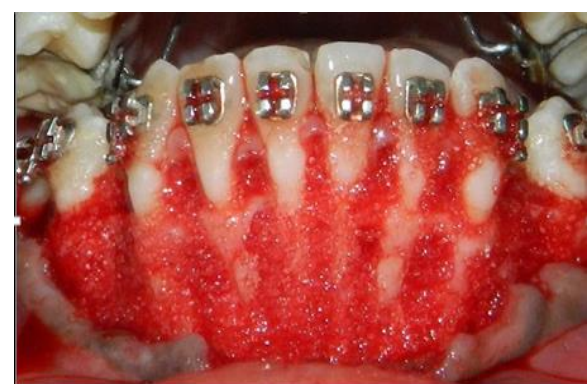

Fig. 1e: Corticotomy cuts covered with bone graft (PerioGlass $^{\circledR}$ )

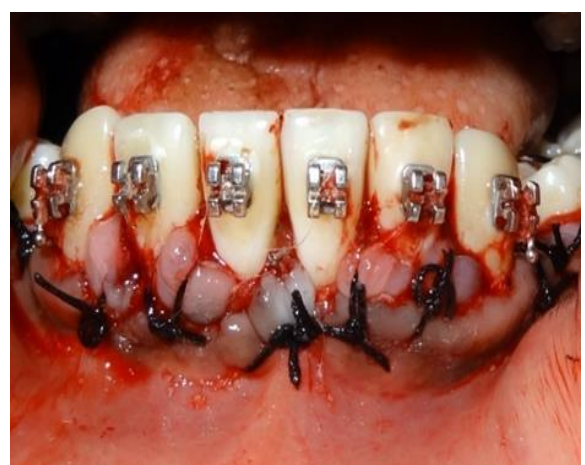

Fig. 1f: Sutures given

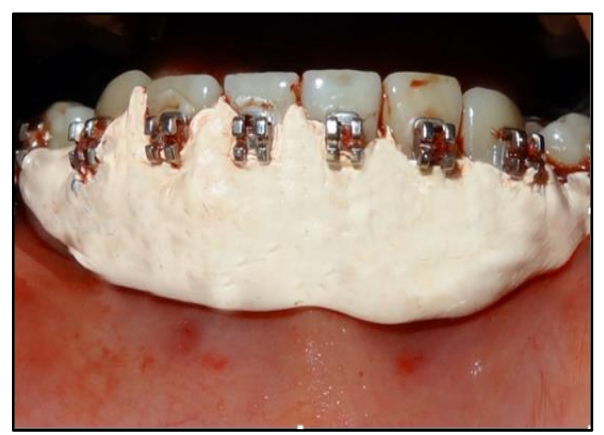

Fig. 1g: Periodontal dressing placed

Group II- PAOO with peizosurgery

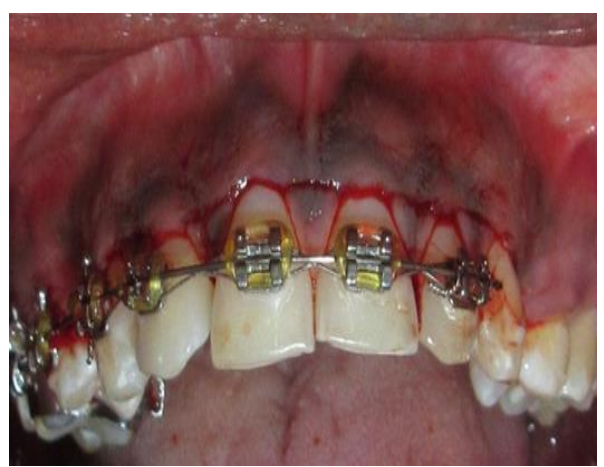

Fig 2a: FiIncisions given

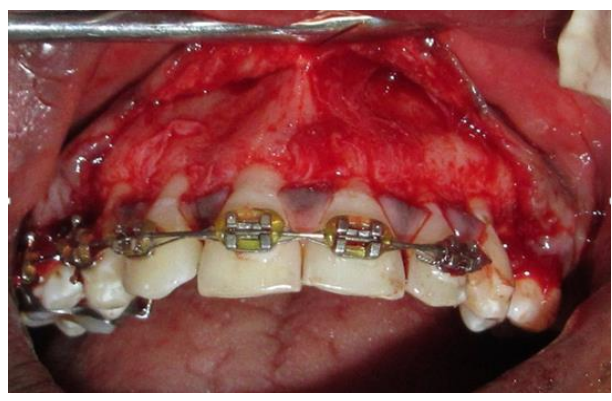

Fig. 2b: Elevation of full thickness flap

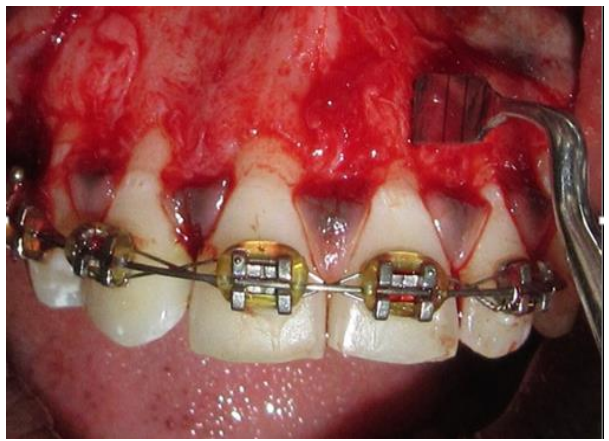

Fig 2c: Placement of vertical cuts by peizosurgical insert tip

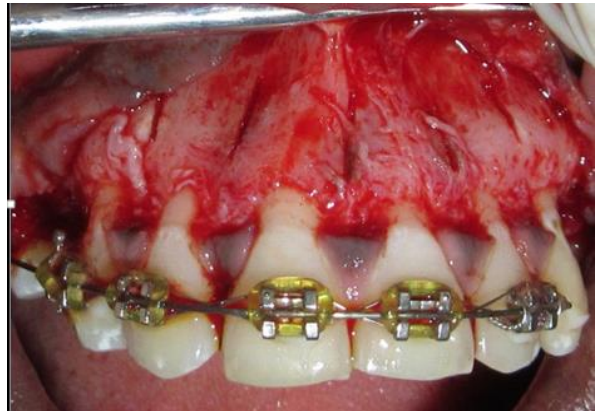

Fig. 2d: Vertical corticotomy cuts given

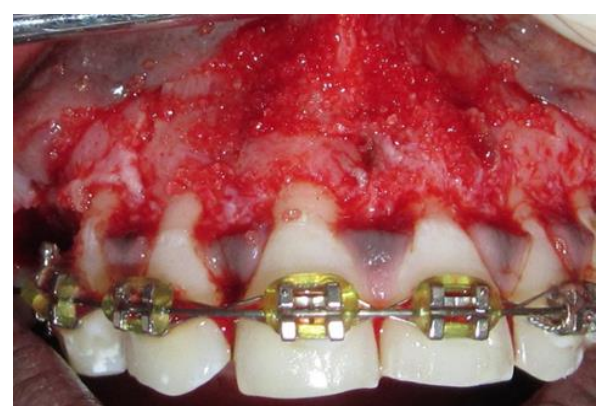

Fig. 2e: Corticotomy cuts covered with bone graft (PerioGlass $^{\circledR}$ ) 


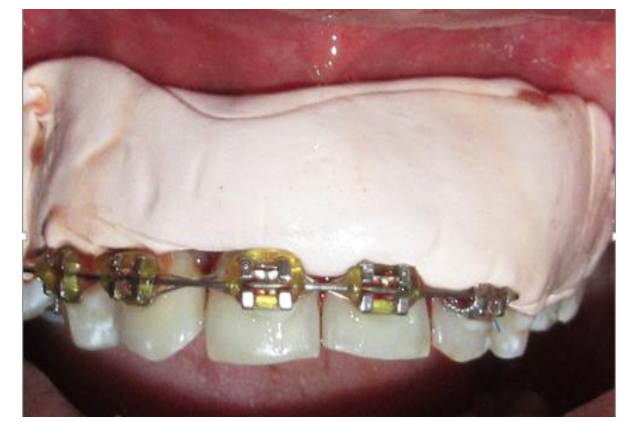

Fig. 2f: Periodontal dressing placed
Measurement of tooth length: Kodak CS CBCT software was used to measure the tooth length from the apex to the incisal edge (Fig. 3). The measuring tool which comes with the software was used to take the measurements.

Sagittal section of the tooth to be measured is focused and fine adjustments were done to find the maximum length of the tooth. At the section where maximum length was observed, measurements were taken using the measuring tool and recorded.

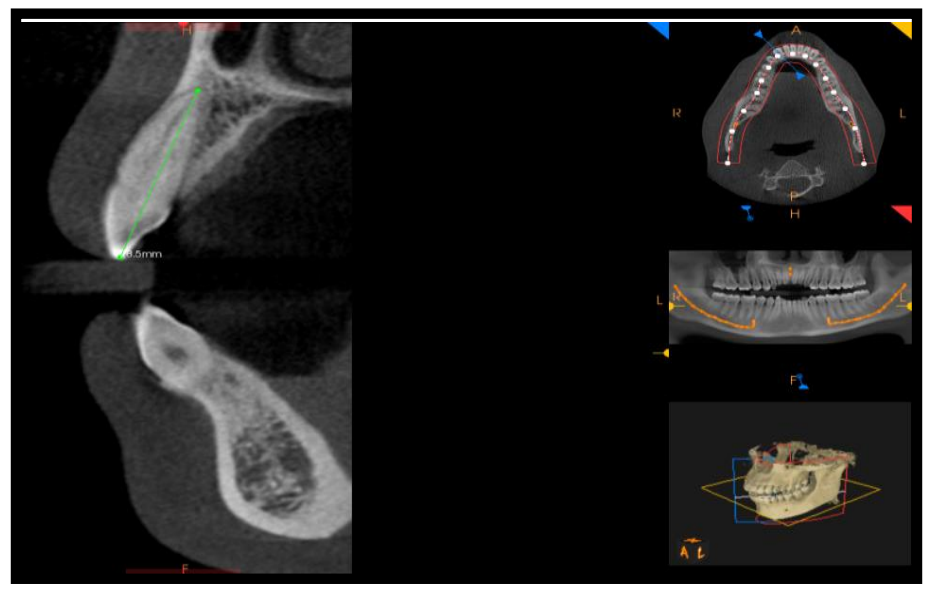

Fig. 3: Measurement of tooth length using measuring tool in CBCT

Measurement of bone density: Cone Beam Computerised Tomography (CBCT) was used to measure the bone density from the mesial side of right second premolar to the mesial side of the left second premolar (Fig. 4).

Mid-sagittal cross sections of the teeth and the interdental areas were focused and an image this area of interest is captured using the "image capture" tool which is default in the Kodak CS software.

These images were evaluated by Image J $1.31 \mathrm{p}$ software (Image J 1.32j, National Institute of Health
USA

available

from http://rsb.info.nih.gov/ij/Java1.31_03). A polygonal tool was selected and a box was created extending $2 \mathrm{~mm}$ from the crest of the alveolar bone to a point $2 \mathrm{~mm}$ apical to the apex of the roots. Grey tone differences from these areas of interest were considered as a value of radiographic density. Interest region radiographic density analysis was done by the histogram tool of Image $\mathbf{J}$ software, which uses a 256 grey tone scale, where zero indicates the black colour and 255 the white one. Data were expressed in arbitrary grey tones.

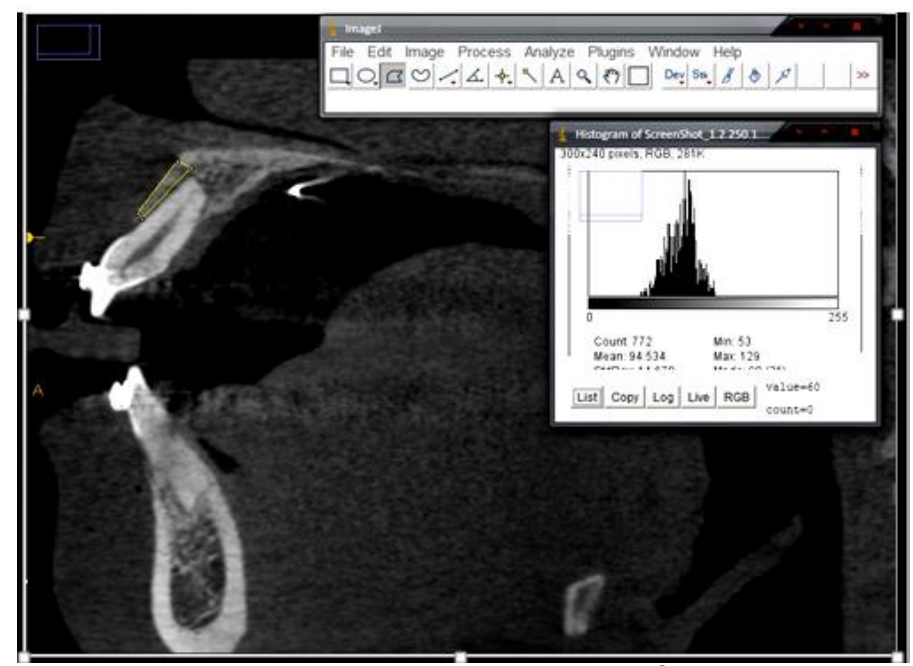

Fig. 4: Measurement of bone density using polygonal tool in Image ${ }^{\circledR}$ software 


\section{Statistical Analysis}

The data was subjected to various statistical test. SPSS software package version 8.0 was used. Student " $\mathrm{t}$ " Test was performed to compare means on the same or related subject over time.

\section{Results}

The statistical power of the study when comparing 40 subjects ( 20 in each group) with the data obtained from measuring bone density and root resorption was found to be $90 \%$.

\section{Treatment Time}

The total measurement for the closure of extraction space during retraction of teeth in maxilla and mandible in Group I and Group II. The amount of retraction done I Space closure was measured at each visit (monthly once) till space closure was over. Group I had a mean retraction of $5.99 \pm 0.5 \mathrm{~mm}$ after 3 months $(\mathrm{p}<0.001)$. Group II had a mean retraction of $7.07 \pm 0.35 \mathrm{~mm}$ $(\mathrm{p}<0.001)$ after 3 months.

Table 1: Comparison of retraction (mm)

\begin{tabular}{|l|c|c|c|c|c|c|}
\hline Retraction & Mean & Std. Deviation & SE of Mean & $\begin{array}{c}\text { Mean } \\
\text { Difference }\end{array}$ & t & P-Value \\
\hline Group 1 & 5.99 & 0.52 & 0.12 & -1.075 & -7.694 & $<0.001^{*}$ \\
\hline Group 2 & 7.07 & 0.35 & 0.08 & & & \\
\hline
\end{tabular}

*denotes significant difference

The mean retraction was found to be higher in Group 2 compared to Group 1 and the difference between them was found to be statistically significant $(\mathrm{P}<0.001)$.

Bone Density: The bone density in Group I (PAOO with surgical bur) \& Group II (PAOO with peizocision) was compared at 0 months and 12 months. There was a significant increase in bone density in both the groups. in Group I- maxilla (121.35 \pm 8.79 to $128.60 \pm 6.61)$ ( $>0.005)$ and mandible $(150.85 \pm 14.55$ to $154.55 \pm 14.93) \quad(\mathrm{p}<0.001)$ and in Group II- maxilla $(120.80 \pm 8.27$ to $125.10 \pm 8.08)$ ( $p>0.05)$ and mandible $(136.35 \pm 11.61$ to $140.70 \pm 11.10) \quad(\mathrm{p}<0.01)$. All the values in both groups in the mandible region were highly statistically significant $(\mathrm{p}<0.01)$.

Table 2: Comparison of bone density in each group between pre-op and post-op: (Paired t-test)

\begin{tabular}{|c|c|c|c|c|c|c|c|c|}
\hline Group & Region & $\begin{array}{c}\text { Time } \\
\text { Interval }\end{array}$ & Mean & $\begin{array}{c}\text { Std. } \\
\text { Deviation }\end{array}$ & $\begin{array}{l}\text { SE of } \\
\text { Mean }\end{array}$ & $\begin{array}{c}\text { Mean } \\
\text { Difference }\end{array}$ & $\mathbf{t}$ & P-Value \\
\hline \multirow[t]{4}{*}{ Group 1} & \multirow[t]{2}{*}{ Maxilla } & Pre-Op & 121.35 & 8.79 & 1.97 & \multirow[t]{2}{*}{-7.250} & \multirow[t]{2}{*}{-4.615} & \multirow[t]{2}{*}{$<0.001 *$} \\
\hline & & Post-Op & 128.60 & 6.61 & 1.48 & & & \\
\hline & \multirow[t]{2}{*}{ Mandible } & Pre-Op & 150.85 & 14.55 & 3.25 & \multirow[t]{2}{*}{-3.700} & \multirow[t]{2}{*}{-2.219} & \multirow[t]{2}{*}{$0.039^{*}$} \\
\hline & & Post-Op & 154.55 & 14.93 & 3.34 & & & \\
\hline \multirow[t]{4}{*}{ Group 2} & \multirow[t]{2}{*}{ Maxilla } & Pre-Op & 120.80 & 8.27 & 1.85 & \multirow[t]{2}{*}{-4.300} & \multirow[t]{2}{*}{-16.376} & \multirow[t]{2}{*}{$<0.001 *$} \\
\hline & & Post-Op & 125.10 & 8.08 & 1.81 & & & \\
\hline & \multirow[t]{2}{*}{ Mandible } & Pre-Op & 136.00 & 11.61 & 2.60 & \multirow[t]{2}{*}{-4.700} & \multirow[t]{2}{*}{-17.899} & \multirow[t]{2}{*}{$<0.001 *$} \\
\hline & & Post-Op & 140.70 & 11.10 & 2.48 & & & \\
\hline
\end{tabular}

*denotes significant difference

1. The increase in mean bone density from pre-op to post-op time interval at maxilla region in Group 1 was found to be statistically significant $(\mathrm{P}<0.001)$.

2. The increase in mean bone density from pre-op to post-op time interval at mandible region in Group 1 was found to be statistically significant $(\mathrm{P}<0.05)$.

3. The increase in mean bone density from pre-op to post-op time interval at maxilla region in Group II was found to be statistically significant $(\mathrm{P}<0.001)$.
4. The increase in mean bone density from pre-op to post-op time interval at mandible region in Group II was found to be statistically significant $(\mathrm{P}<0.001)$.

\section{Root Resorption}

The total lengths of each tooth from canine to canine in both the arches were measured at baseline (0months) as well as 12 months to determine the root resorption by CBCT.

Table 3: Comparison of tooth length in each group between Pre-Op and Post-Op: (Paired t-test)

\begin{tabular}{|c|c|l|l|c|c|c|c|c|}
\hline Group & Region & $\begin{array}{c}\text { Time } \\
\text { Interval }\end{array}$ & Mean & $\begin{array}{c}\text { Std. } \\
\text { Deviation }\end{array}$ & $\begin{array}{c}\text { SE of } \\
\text { Mean }\end{array}$ & $\begin{array}{c}\text { Mean } \\
\text { Difference }\end{array}$ & t & P-Value \\
\hline \multirow{3}{*}{ Group 1 } & \multirow{2}{*}{ Maxilla } & Pre-Op & 23.68 & 1.71 & 0.38 & 0.450 & 9.828 & $<0.001^{*}$ \\
\cline { 3 - 7 } & & Post-Op & 23.23 & 1.74 & 0.39 & & & \\
\cline { 2 - 9 } & \multirow{2}{*}{ Mandible } & Pre-Op & 25.05 & 1.33 & 0.30 & 0.404 & 14.221 & $<0.001^{*}$ \\
\cline { 3 - 6 } & & Post-Op & 24.65 & 1.32 & 0.30 & & & \\
\hline
\end{tabular}




\begin{tabular}{|l|l|l|l|l|l|l|l|l|}
\hline Group 2 & \multirow{2}{*}{ Maxilla } & Pre-Op & 22.75 & 1.85 & 0.41 & 0.736 & 4.067 & $0.001^{*}$ \\
\cline { 3 - 6 } & & Post-Op & 22.02 & 1.84 & 0.41 & & & \\
\cline { 2 - 10 } & \multirow{2}{*}{ Mandible } & Pre-Op & 21.03 & 2.79 & 0.62 & 0.548 & 7.786 & $<0.001^{*}$ \\
\cline { 3 - 8 } & & Post-Op & 20.48 & 2.78 & 0.62 & & & \\
\hline
\end{tabular}

$*$ denotes significant difference

The decrease in mean tooth length from pre-op to post-op time interval at maxilla region $(\mathrm{P}<0.001)$ and at mandible region $(\mathrm{P}<0.05)$ in Group 1 was found to be statistically significant The decrease in mean tooth length from pre-op to post-op time interval at maxilla region $(\mathrm{P}<0.01)$ at mandible region $(\mathrm{P}<0.001)$ was found to be statistically significant and Statistically very significant respectively.

\section{Discussion}

Adult subjects who seek orthodontic treatment often desire that their treatment be completed in a shorter span of time. In recent decades major attempts have been made to shorten the length of treatment. These techniques include rapid distraction of the canines and corticotomy-facilitated orthodontics.

Periodontally Accelrated Osteogenic Orthodontics offered the benefits of enhanced scope of malocclusion treatment by reduction of extraction and /or orthognathic surgery, three to four times more rapid orthodontic treatment compared to conventional approach, higher degree of stability in clinical outcomes, less relapse, increased alveolar bone volume and enhanced periodontal health. ${ }^{13}$

Nightingale et al $2003^{14}$ used Force level of 200grams per side in their study. Based on clinical research. Force levels of 60-300 grams produce an average tooth movement rates of approximately $1 \mathrm{~mm}$ per month in humans. Since Regional Acceleratory Phenomenon brings about transient osteopenia and increase in bone turnover rate, even with same force level, higher rate of tooth movement was observed in study group. This is contrary to the study done by Kim $\mathrm{SH}$ et al in 2009. ${ }^{15}$ where mini implants were used to provide more anchorage and an increased orthodontic force was used. In this study, retraction was started two weeks post-surgery as recommended by Wilcko et al. ${ }^{15}$

The reason for the 2 weeks is to maximize the exploitation of the three- to four-month limited window of opportunity following RAP, where the bone is more pliable allowing to move teeth rapidly through the demineralized bone matrix as reported by Lee et al. ${ }^{15-17}$ This window of opportunity lasts for a few months before the alveolar bone remineralization occurs creating a localized spatiotemporal window of opportunity. Also two weeks delay between surgery and initiation of retraction was followed so that the postoperative pain and swelling could subside in the subjects.

Mean rate of retraction of anterior teeth in both group were compared, and significant difference was noted between the two groups. Rate of retraction in
Group I (PAOO with surgical bur) was $5.99 \mathrm{~mm} / 3$ months and rate of retraction in Group II (PAOO with peizocision was $7.07 \mathrm{~mm} / 3$ months. In subjects where corticotomy with surgical bur was carried out, faster tooth movement was observed in comparison to PAOO with peizocision.

In the present study, the total retraction time in Group I (PAOO with surgical bur) was 20.81 weeks (5 months and 2 weeks) and the total retraction time in Group II (PAOO with peizocision) was 28.48 weeks. (7 months and 1 week). The current findings corroborate the clinical observations of Wilcko et al. 2001, 2003 and Hajji et al 2001 Wilcko et al 2009..$^{15-20}$ who reported similar significant reductions in treatment times and found that the accelerated osteogenic orthodontics technique provides efficient and stable orthodontic tooth movement. Wilcko et al. $2011^{21}$ reported an average of 6.1 months of treatment duration for PAOO.

In the present study we used CBCT for the evaluation of bone density, for measuring the tooth length. Computed tomographic scanning was performed in order to assess the dento-alveolar morphology in sagital dimension where cephalometric findings fail to reveal due to surrounding bone superimpositions. For this reason 3-D evaluation is required which could provide 3 dimensional displacement for dento-alveolar changes. ${ }^{22}$ This is in agreement with the study done by Leung $\mathrm{CC}$ et al in $2010{ }^{23}$ that supports the fact that CBCT is an accurate and reliable method for measuring bone density and bony dehiscence and fenestrations.

However, in the present study, post treatment CBCT showed a minimal amount of root resorption in Group I which was around $0.34 \mathrm{~mm}$ and that of Group II was around $0.51 \mathrm{~mm}$ Whereas studies done by Ong et al $2002{ }^{23}$ showed mean shortening of root in central incisors to be $0.23 \mathrm{~mm}$ in PAOO group and $0.52 \mathrm{~mm}$ in conventional orthodontic group. In a past study a post active treatment panorama showed some tendency of root-end resorption with orthodontic movement alone. orthodontic treatment-related risk factors for apical root resorption include; the treatment duration, magnitude of applied force, direction of tooth movement, amount of apical displacement and method of force application ${ }^{24}$ The findings are in agreement with findings done by Kurol et al. $1998^{25}$ and wilcko et al 2003..$^{26,27}$

The results of the present study are not in accordance with the studies done by Levander et al. $(2000)^{28}$ and Artun et al. $(2009)^{29}$ Jacobs et al $2014^{30}$ wherein they reported that, after 3 months of treatment, apical root resorption was detected in only a few teeth, but the number of affected teeth increased significantly 
after 6 months of treatment. They also stated that patients with detectable root resorption during the first 6 months of active treatment are more likely to experience resorption during the following 6-month period.

In the present study there was an increase in bone density in both the groups with increase in bone density observed in the group with PAOO and surgical bur. This might be attributed to the presence of the combination of bone grafting material and the transient osteopenia resulting from the selected corticotomy. Osteopenia led to increase in bone turnover, rapid removal of the hyalinized areas, and decrease of bone density in the region of tooth movement .This condition favors tooth movement with reduced root resorption.

Since most of what is known about the decortication procedures in orthodontic treatment is based on case reports, more laboratory and clinical studies are necessary to better explain the biological mechanisms involved at both the tissue and molecular level, and most importantly, investigate the long term effects of this procedure. 12 months is not sufficient to analyze the long term effects of PAOO. Even though the sample size of this study was less, the power of the study was $90 \%$. It is recommended that further multicenter studies employing large study populations and longer evaluation time periods are required.

\section{Conclusion}

The PAOO procedure provides a safe alternative for patients with moderate to severe crowding who desire the benefits of orthodontic treatment in a relatively short period of time. PAOO enhances bone remodeling and augmentation, accelerates tooth movement and significantly reduces the duration of treatment. In the present study, post treatment CBCT showed a minimal amount of root resorption in Group I which was around $0.34 \mathrm{~mm}$ and that of Group II was around $0.51 \mathrm{~mm}$ and increase in the bone density was seen in the post- operative CBCT.

Drawback: The procedure of corticotomy with piezocision and surgical bur is a very tedious and elongative procedure for patients due to which patients tried to delay or miss the appointment but surprisingly very less patient attrition was seen in our study.

\section{References}

1. Pathak TS, Kini V, Kanagotagi S, Balasubramanian K, Gupta H. Wilckodontics. J Contemp Dent. 2013;3(1):1519.

2. Buschang PH, Campbell PM, Ruso S. Accelerating Tooth Movement With Corticotomies: Is It Possible and Desirable. Seminars in Orthodontics. 2012;18:286-94.

3. Fink DF, Smith RJ. The duration of orthodontic treatment. Am J Orthod Dentofacial Orthop 1992;102:4551.

4. Skidmore KJ, Brook KJ, Thomson WM, Harding WJ. Factors influencing treatment time in orthodontic patients. Am J Orthod Dentofacial Orthop. 2006;129:23038.

5. Fisher MA, Wenger RM, Hans MG. Pretreatment characteristics associated with orthodontic treatment duration. Am J Orthod Dentofacial Orthop. 2010;137:178-86.

6. Kurol, Owman-Moll P, Lundgren D. Time-related root resorption after application of a controlled continuous orthodontic force. Am J Orthod Dentofacial Orthop. 1996;110:303-10.

7. Segal GR, Schiffman PH, Tuncay OC. Meta analysis of the treatment-related factors of external apical root resorption. Orthod Craniofac Res. 2004;7:71-78.

8. Artun J, Brobakken BO. Prevalence of carious white spots after orthodontic treatment with multibonded appliances. Eur J Orthod. 1986;8:229-34.

9. Ristic M, Vlahovic Svabic M, Sasic M, Zelic O. Clinical and microbiological effects of fixed orthodontic appliances on periodontal tissues in adolescents. Orthod Craniofac Res. 2007;10:187-95.

10. Flavio Uribe, Nandakumar Janakiram. Corticotomyassisted molar protraction with the aid of temporary anchorage device. Angle orthodontist. 2013:1-10.

11. Cadenas de Llano-Pérula. Surgically-based methods to modify orthodontic tooth movement: A literature review. Edorium J Dent. 2015;2:35-42.

12. Ashish Jain, Tarun Das, Rashi Chaturvedi. One-stage Surgical Alveolar Augmentation (PAOO) For Rapid Orthodontic Movement. A Case Report. Indian J of Dental Sciences. 2011;3(4):18-21.

13. Walmsley AD, Laird WR, Williams AR, Dental plaque removal by cavitational activity during ultrasonic scaling. J Clin Periodontol. 1988;15:539-43.

14. McBride MD, Campbell PM, Opperman LA, Dechow PC. How does the amount of surgical insult affect bone around moving teeth. Am J Oethod Dentofacial Orthop. 2014; 145:92-99.

15. Wilcko WM, Wilcko T, Bouquot JE, Ferguson DJ. Rapid orthodontics with alveolar reshaping: two case reports of decrowding. Int J Periodontics Restorative Dent. 2001;21(1):9-19.

16. Dibart S. Rapid Treatment of Class II Malocclusion with Piezocision: Two Case Reports. Int J Periodontics Restorative Dent. 2010;30:487-93.

17. Lee W, Karapetyan G, Moats R, Yamashita D, Moon HB, Ferguson D, Yen S. Corticotomy / Osteotomy -assisted tooth movement micro CT's differ. J Dent Res. 2008; 87:861-67.

18. Wilcko WM, Ferguson DJ, Bouquot JE, Wilcko MT. Rapid orthodontic decrowding with alveolar augmentation: case report. World J Orthod. 2003;4:197205.

19. Hajji SS. The influence of accelerated osteogenic response on mandibular de- crowding. J Dent Res. 2001;80:80

20. Wilcko MT, Wilcko WM, Pulver JJ, Bissada NF, Bouqout JE. Accelrated osteogenic orthodontics technique: stage surgically facilitated rapid orthodontic technique with alveolar augmentation. J Oral Max Surg . 2009;67:2149-2159.

21. Sebaoun JDM, Surmenian J, Dibart S. Accelerated orthodontic treatments with Piezocision: a mini-invasive alternative to alveolar corticotomies. Orthod Fr. 2011;82:311-19

22. Guo QY, Zhang SJ, Liu H, Wang CL, Wei FL, Tao LV, et al. Three-dimensional evaluation of upper anterior alveolar bone dehiscence after incisor retraction and intrusion in adult patients with bimaxillary protrusion 
malocclusion Guo et al. J Zhejiang Univ-Sci. 2011;12:990-97.

23. Leung CC, Palomo L, Griffith R, Hans MG. Accuracy and reliability of cone-beam computed tomography for measuring alveolar bone height and detecting bony dehiscences and fenestrations. Am J Orthod Dentofacial Orthop. 2010;137:109-19

24. Weltman B, Vig KWL, Fields HW, Shanker S, Kaizer EE. Root resorption associated with orthodontic tooth movement: A systematic review. Am J Orthod Dentofacial Orthop. 2010;137:462-76.

25. Kurol, J., P.Owman-Mol. .Hyalinization and root resorption during early orthodontic tooth movement in adolescents. Angle Orthod. 1998; 68:161-65.

26. Wilcko WM, Ferguson DJ, Bouquot JE, Wilcko MT. Rapid orthodontic decrowding with alveolar augmentation: case report. World J Orthod. 2003;4:197205.

27. Ong MM, Wang HL. Periodontic and orthodontic treatment in adults. Am J Orthodont Dentofacial Orthoped. $2002 ; 122: 420-28$.

28. Levander E, Malmgren O: Long-term follow-up of maxillary incisors with severe apical root resorption. Eur J Orthod. 2000;22:85-92.

29. Artun J, Van 't Hullenaar R R, Doppel D, KuijpersJagtman AM: Identification of orthodontic patients at risk of severe apical root resorption. Am J Orthod Dentofacial Orthop. 2009;135:448-55.

30. Jacobs C, Gebhardt PF, Jacobs V. Root resorption, treatment time and extraction rate during orthodontic treatment with self-ligating and conventional brackets. Head \& Face Medicine. 2014;10:2. 